\title{
Analisis High Order Thinking Skills (HOTS) Taksonomi Berpikir Kritis pada Permasalahan Fisika

\author{
Syaiful Rochman*, Nirwana
}

Fakultas Keguruan dan Ilmu Pendidikan Universitas Bengkulu

*Email: srochman@unib.ac.id

DOI: https://doi.org/10.33369/pendipa.4.2.40-44

\begin{abstract}
The purpose of this research is to get the measurement result as a description of higher order thinking skill in taxonomy to critical thinking physics problem in SMA XI class. This study is descriptive qualitative through three stages, namely: initial development of the instrument, content validation and empirical, and measurement. The research has been conducted in the region of Central Bengkulu. The instrument used has been validated by the expert and applied rasch model. An empirical valiadation test was conducted by 95 students. A valid instrument is used to measure student's higher order thinking skills. The number of learners measured using a total sampling of 148 learners. The measurement result shows very high critical thinking 0,5\%, ability critical thinking high 25\%, ability medium critical thinking 55\%, ability critical thinking low 19\%, ability critical thinking very low 0, 5\%. On the average it can be concluded that higher order thinking skills on taxonomy critical thinking students in Bengkulu Tengah included in medium criterion.
\end{abstract}

Keywords: HOTS, Critical Thinking (C5), physics.

[ABSTRAK] Tujuan penelitian adalah mendapatkan hasil pengukuran higher order thinking skills (HOTS) pada taksonomi berpikir kritis permasalahan fisika di SMA kelas XI. Penelitian ini adalah deskriptif kualitatif melalui tiga tahapan, yakni: pengembangan awal instrumen, validasi isi dan empiris, dan pengukuran. Penelitian telah dilaksanakan di wilayah Kabupaten Bengkulu Tengah. Instrumen yang digunakan telah divalidasi oleh ahli dan telah menerapkan pemodelan rasch. Uji coba valiadasi secara empiris dilaksanakan oleh 95 siswa. Instrument yang sudah valid digunakan untuk mengukur higher order thinking skills siswa. Jumlah siswa yang diukur menggunakan total sampling sebanyak 148 siswa. Hasil pengukuran menunjukkan kemampuan berpikir kritis sangat tinggi 0,5\%, kemampuan berpikir kritis tinggi 25\%, kemampuan berpikir kritis sedang $55 \%$, kemampuan berpikir kritis rendah $19 \%$, kemampuan menganalisis sangat rendah berpikir kritis $0,5 \%$. Secara rata-rata dapat disimpulkan bahwa higher order thinking skills pada taksonomi berpikir kritis siswa di Kabupaten Bengkulu Tengah termasuk dalam kreteria sedang.

Kata kunci: HOTS, Berpikir Kritis (C5), Fisika.

\section{PENDAHULUAN}

Persaingan industri 4.0 yang telah dihadapi oleh Indonesia mengharapkan para siswa saat ini mampu mencapai berbagai kompetensi level Higher Order Thinking Skills (HOTS). Kompetensi tersebut, yaitu berpikir kritis (criticial thinking), kreatif dan inovasi (creative and innovative), kemampuan berkomunikasi (communication skill), kemampuan bekerja sama (collaboration) dan kepercayaan diri (confidence).

Pengembangan pembelajaran berorientasi pada keterampilan HOTS merupakan program yang dikembangkan sebagai upaya Kementerian Pendidikan dan Kebudayaan melalui Direktorat 
Jenderal Guru dan Tenaga Kependidikan (Ditjen Pendidikan, 2018). Dalam upaya peningkatan kualitas pembelajaran dan lulusan tersebut, program ini dikembangkan mengikuti arah yang terintegrasi pada penguatan pendidikan karakter. Selanjutnya tidak meninggalkan pembelajaran yang berorientasi pada proses dan evaluasi pembelajaran HOTS.

Kemampuan sains siswa Indonesia berada pada posisi 62 dari 69 negara yang dievaluasi Programme for International Students Assessment (PISA) (OECD, 2016). Selanjutnya data Trends International Mathematics and Science Study (TIMSS,2015) menunjukkan bahwa kemampuan Indonesia dalam sains pada peringkat 48 dari 50 negara peserta dengan skor rata-rata 39 poin dari 500 poin. Gardner (2013) memiliki pandangan bahwa pembelajaran fisika seharusnya mendorong dan memotivasi siswa agar belajar aktif dan kreatif.

Kreativitas dibutuhkan untuk diterapkan dalam sains, teknologi, dan seni dalam kehidupan seharihari (Runco, 2014). Hal tersebut dikarenakan bahwa HOTS berhubungan dengan kreativitas. Studi lain mengemukanan bahwa kreativitas memiliki hubungan dengan proses penemuan untuk menyelesaikan masalah (Cropley, 2001). Guru yang sudah sarjana sudah memaknai bahwa kretaivitas memiliki manfaat (Batey, 2012; Batey \& Furnham, 2006; Kaufmann \& Baer, 2012;) untuk menghasilkan pemikiran baru, solusi, dan jawaban (Duff, Kurczek, Rubin, Cohen \& Tranel, 2013) yang berhubungan dengan pemecahan masalah (Crilly, 2010; Lewis, 2005; Smith, 2013). Dengan demikian, pemikiran kreatif sangat dibutuhkan untuk menyelesaikan masalah yang tidak terduga.

Masalah fisika merupakan tantangan yang dihadapi oleh siswa sebagai upaya untuk mencapai tujuan hasil pembelajaran. Masalah umumnya diselesaikan dengan cara konvensional. Sebaliknya, masalah yang tidak biasa (non-konvensional) membutuhkan HOTS untuk menyelsaikannya, misalnya konsep dan fenomena alam yang baru. Sockalingam dan Schmidt (2011) menjelaskan bahwa masalah baru menantang pemikiran dan pembelajaran siswa.

Tujuan hasil pengukuran HOTS ini adalah mengetahui Level siswa dalam taksonomi berpikir kreatif. Hasil yang didapatkan dalam pengukuran berdasarkan ranah kognitif taksonomi Bloom (C5) yang meliputi mengevaluasi, mengkritik, dan memeriksa. Hasil penelitian ini memberikan kontribusi dalam Pendidikan level kemampuan siswa dalam menyelesaikan masalah kompleks dalam mata pelajaran fisika. Kontribusi yang diberikan adalah hasil penilaian (assessment) kemampuan siswa untuk memperbaiki pembelajaran fisika sehingga diarahkan pada pembelajaran berbasis HOTS.

\section{METODE PENELITIAN}

Penelitian ini merupakan penelitian deskriptif kualitatif dan telah mengembangkan instrumen evaluasi. Penelitian ini menghasilkan informasi tentang kemampuan siswa SMA kelas XI level C5 di seluruh Kabupaten Bengkulu Tengah. Pembuatan tes terdiri atas: perangkat tes dan uji coba konten oleh ahli. Setelah perancangan tes selesai, tes divalidasi oleh ahli, jika ada item yang belum memenuhi syarat dilakukan revisi terlebih dahulu sampai tes valid secara konten. Setelah valid secara konten selanjutnya dilakukan validasi empiris. Berdasarkan hasil uji coba, item yang tidak fit terhadap model rasch dikeluarkan atau diperbaiki dan butir soal yang fit digunakan untuk mengukur HOTS fisika.

\section{Waktu dan Tempat Penelitian}

Penelitian dilaksanakan di SMA kelas XI wilayah Kabupaten Bengkulu Tengah terhadap HOTS dalam taksonomi Evaluasi (C5).

\section{Subjek Penelitian}

Populasi penelitian ini adalah siswa yang berada di SMA Kabupaten Bengkulu Tengah kelas XI IPA. Jumlah sekolah SMA di Bengkulu Tengah adalah 6 sekolah. Jumlah responden adalah sebanyak 148 siswa.

\section{Intrumen, dan Teknik Pengumpulan Data}

Instrumen pengumpulan data berupa perangkat tes. Data yang terkumpul akan diinput ke dalam Excel yang dikonversikan dalam notepad. Data yang telah diperoleh beserta jawaban diberikan skor dengan empat kategori, yaitu 1,2,3, atau 4. Penentuan skor siswa mengacu pada penskoran politomus. 
Instrumen yang digunakan dalam penelitian adalah instrumen tes. Instrumen tes berbentuk soal pilihan ganda beralasan dengan empat pilihan A, B, C, dan D. Instrumen alat ukur kemampuan siswa mengenai HOTS meliputi: 1) kisi-kisi instrumen, tujuan penyusunan kisi-kisi tes adalah membatasi ruang lingkup dan tekanan penilaian, sehingga dapat dijadikan panduan dalam menulis butir tes, 2) perangkat tes dan lembar jawaban, Naskah perangkat tes berupa butir soal pilihan ganda beralasan dengan lima pilihan alternatif pilihan jawaban. Jumlah tes yang akan diujikan dalam tahap uji coba sebanyak 50 butir tes sedangkan yang digunakan dalam pengukuran sebanyak 36 butir tes. dan 3) lembar validasi, Lembar lembar validasi yang perlu dinilai meliputi aspek konstruksi, aspek bahasa, dan aspek materi. Lembar validasi diberikan kepada dua orang validator yang akan menentukan validasi tes secara teoritis.

\section{Teknik Analisis Data}

Analisi data yang diterapkan adalah mencari validasi, reliabilitas, tingkat kesukaran, dan normalitas pada uji coba empiris. Guna memudahkan analisis, data analisis penelitian dianalisis dengan menggunakan bantuan komputer program Microsoft Exel Office 2010, SPSS, dan winstep3.73.

Analisis data kualitatif dilakukan oleh validator ahli mengnai butir tes yang dilihat dari segi materi, konstruksi, dan bahasa. Validasi isi ini dilakukan sebelum butir tes digunakan. Lembar jawaban siswa yang telah dikoreksi akan dianalisis secara kuantitatif. Analisis kuantitatif menggunakan skala polinomius dengan model rasch. Data yang telah dimasukkan dalam format dan susunan notepad dianalisis menggunakan program winsteps dan excel 2010.

Pada analisis data pengukuran kemampuan siswa dianalisis menggunakan program Microsoft Excel yang nantinya akan terbagi menjadi lima kategori kreteria. Penetapan standar kelulusan atau standar pencapaian kompetensi mengunakan standar yang diadaptasi dari tanwey adalah 60\%, maka acuan yang dapat digunakan $90 \% \leq x$ maka "A (sangat tinggi)", $75 \% \leq x<90$ maka "B (tinggi)", $60 \% \leq x<75 \%$ maka "C ( sedang)",
$40 \% \leq x<60 \%$ maka "D (rendah)", dan jika $x<$ $40 \%$ maka "E (sangat rendah)".

\section{HASIL DAN PEMBAHASAN}

Hasil pengukuran secara keseluruhan dapat dilihat pada gambar 1. Hasil kemampuan menunjukkan kemampuan berpikir kritis sangat tinggi $0,5 \%$, kemampuan berpikir kritis tinggi $25 \%$, kemampuan berpikir kritis sedang $55 \%$, kemampuan berpikir kritis rendah $19 \%$, kemampuan menganalisis sangat rendah berpikir kritis $0,5 \%$.

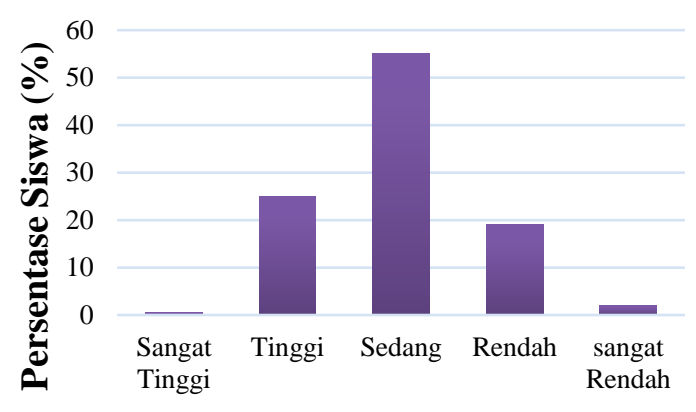

Level Kemampuan

Gambar 1. Grafik Hasil Kemampuan HOTS taksonomi Critical Thinking

Hasil penelitian menunjukkan bahwa kemampuan HOTS siswa pada ranah critical thinking banyak dikuasai siswa pada level sedang. Hal tersebut disebabkan oleh faktor kemampuan pengecekan informasi dan evaluasi sehingga memungkinkan siswa memiliki kemampuan untuk fase penemuan. Hasil ini sejalan dengan Espey (2017) yang menyatakan bahwa keterampilan kritis dapat meningkat sejalan dengan pembiasaan pengelolaan informasi. Faktor lain Hadir untuk pengembangan kemampuan pada ranah SMA masih tergolong sedang. Hal tersebut sejalan dengan Dalgleish, Girard, \& Davies (2017) yang menyatakan bahwa posisi berpikir kritis serta keterampilan, dan mengadopsi memiliki faktor penting dalam sebuah pemecahan masalah. 
Berdasarkan Gambar 2 dapat dilihat bahwa siswa yang memiliki HOTS ranah kemampuan mengevaluasi (evaluating) yang termasuk kategori sangat tinggi adalah 0 siswa atau $0 \%$, termasuk kategori tinggi 37 siswa atau $25 \%$, termasuk kategori Sedang 82 siswa atau 55\%, termasuk Kategori Rendah 28 siswa atau $18 \%$, Kategori sangat Rendah 2 siswa atau $2 \%$.

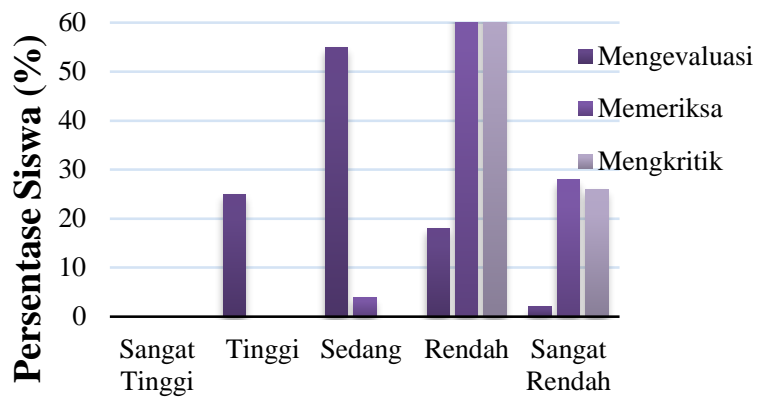

Level Kemampuan

Gambar 2. Grafik persentase Kemampuan Siswa

Pada ranah ini kemampuan peserta didik paling tergolong dalam kemampuan sedang, yaitu 82 siswa. Hal ini disebabkan oleh pola respons yang menunjukkan logika dan penalaran serta strategi dan solusi pendukung yang untuk berpikir evaluatif. Hasil ini didukung oleh hubungan antara pemikiran kritis dan metakognisi (Arslan, 2014; Başbay, 2013; Magno, 2010).

Berdasarkan Gambar 2 dapat dilihat bahwa siswa yang memiliki HOTS ranah kemampuan Memeriksa (Checking) yang termasuk kategori sangat tinggi adalah 0 siswa atau $0 \%$, termasuk kategori tinggi 0 siswa atau $0 \%$, termasuk kategori Sedang 5 siswa atau 4\%, termasuk Kategori Rendah 102 siswa atau $68 \%$, Kategori sangat Rendah 41 siswa atau $28 \%$.

Kemampuan memeriksa merupakan kategori yang sangat rendah, hal tersebut disebabkan oleh kemampuan analisis faktor fenomena fisika. Hal tersebut menyebabkan kemampuan siswa dalam mengungkapkan permasalahan rendah. Masingmasing faktor yang mewakili hal ini didukung oleh Bernstein dan Issac (2018) yang menyatakn bahwa kelemahan dalam kemampuan memeriksa akan mempengaruhi persepsi dan akan melakukan penolakan dengan informasi baru yang lebih baik

Berdasarkan Gambar 2 dapat dilihat bahwa siswa yang memiliki HOTS ranah kemampuan Mengkritik (Critiquin) yang termasuk kategori sangat tinggi adalah 0 siswa atau $0 \%$, termasuk kategori tinggi 0 siswa atau $0 \%$, termasuk kategori Sedang 0siswa atau 0\%, termasuk Kategori Rendah 110 siswa atau $74 \%$, Kategori sangat Rendah 38 siswa atau $26 \%$.

Berpikir kritis mempengaruhi kemampuan HOTS. Pada kemampuan mengkrtitik rendah disebabkan oleh faktor pemecahan masalah yang tidak rutin diterapkan oleh guru kepada siswa. kemampuan HOTS siswa di kelas tentang penyelidikan akan menjadikan bermakna dan pembelajaran yang berpusat pada siswa dapat kembangkan. Hal ini sejalan bahwa siswa mampu menunjukkan kemampuan interpretasi, analisis, evaluasi, inferensi dan penjelasan mereka (Ulger, 2018; Susianti, Salmi, dan Hidayah, 2018).

Penyebaran HOTS pada setiap sekolah juga termasuk sedang karena peserta didik termasuk dalam kategori sedang berada pada angka lebih dari 50\%. Penyebabnya adalah sistem pembelajaran yang mirip yaitu menggunakan ceramah, penugasan, dan catatan. Ditemukan bahwa pembelajaran sistem penugasan paling tinggi masih dalam kreteri analisis (C4). Selain $\mathrm{C} 4$, yang paling sering digunakan adalah ingatan (C1), pemahaman (C2), dan aplikasi (C3). Faktor tersebut menyebabkan kemampuan siswa menjadi Low Order Thinking (LOT) dan tidak terbiasa dalam HOTS khususnya pada taksonomi kritis. Kuswana (2011) menyatakan hal yang mendukung bahwa penerapan dan pembiasakan kerja otak untuk menempatkan keahlian yang meliputi analisis, menyimpulkan, dan evaluasi akan mendukung kinerja otak dalam mencapai HOTS. 


\section{KESIMPULAN}

Hasil pengukuran menunjukkan kemampuan berpikir kritis sangat tinggi 0,5\%, kemampuan berpikir kritis tinggi $25 \%$, kemampuan berpikir kritis sedang $55 \%$, kemampuan berpikir kritis rendah $19 \%$, kemampuan menganalisis sangat rendah berpikir kritis $0,5 \%$. Secara rata-rata dapat disimpulkan bahwa HOTS pada taksonomi berpikir kritis siswa di Kabupaten Bengkulu Tengah termasuk dalam kreteria sedang.

\section{DAFTAR PUSTAKA}

Arslan, S. (2014). An Investigation of the relationships between Metacognition and Self Regulation with structural equation. International Online Journal of Educational Sciences, 6 (3), 603-611.

Başbay, M. (2013).Analysing the relationship of Critical Thinking and Metacognition with epistemological beliefs through structural equation modeling. Education and Science, 38, 169.

Batey, M., \& Furnham, A. (2006). Creativity, intelligence, and personality: A critical review of the scattered literature. Genetic, Social, and General Psychology Monographs, 132(4), 355429.

Batey, M. (2012). The measurement of creativity: From definitional consensus to the introduction of a new heuristic framework. Creativity Research Journal, 24(1), 55-65. https://doi.org/10.1080/10400419.2012.649181

Bernstein, Arla G. and Isaac Carol. (2018). Critical Thinking Criteria for Evaluating Online Discussion. . International Online Journal of Educational. Vol. 12, No. 2, Art. 11

Crilly, N. (2010). The structure of design revolutions: Kuhnian paradigm shifts in creative problem solving. Design Issues, 26(1), 54-66. Retrieved from https://www.jstor .org/stable/pdf/20627842.pdf

Cropley, A. J. (2001). Creativity in education and learning. London: Kogan Page

Dalgleish, Patrick Girard, and Maree Davies, 2017, "Critical Thinking, Bias and Feminist Philosophy: Building a Better Framework through Collaboration", Informal Logic, 37(4): 351-369.
Ditjen Pendidikan dan kebuayaan. (2018). Direktorat Jenderal Pendidikan Dasar dan Menengah. Diambil dari http://dikdasmen.kemdikbud.go.id/

Duff, M. C., Kurczek, J., Rubin, R., Cohen, N. J., \& Tranel, D. (2013). Hippocampal amnesia disrupts creative thinking. Hippocampus, 23(12), 1143-1149. https://doi.org/10.1002/hipo.22208

Gardner, Howard. (2013). Multiple Intelligences (terjemahanYelvi Andri Zaimul). New York : Basic Books. (buku asli terbitan tahun 2006).

Kaufmann, J., \& Baer, J. (2012). Beyond new and appropriate: Who decides what is creative? Creativity Research Journal, 24(1),83-91.

Kuswana.W.S. (2011). Taksonomi Berpikir. Bandung: Rosda Karya.

Lewis, T. (2005). Creativity-A framework for the design/ problem solving discourse in technology education. Journal of Technology Education, 17(1), 35-52.

Magno,C. (2010). The role of metacognitive skills in developing critical thinking. Metacognition Learning, 5:137-156. DOI 10.1007/s11409-0109054-4

Molly, Espey. (2017) Enhancing Critical Thinking Using Team-Based Learning. Pages 15-29.

OECD. PISA (Programme for International Student Assessment. [online]. Tersedi: https://www.oecd.org/pisa/data

Runco, M. A. (2014). Creativity (2nd ed.). Boston, MA: Academic Press.

Sockalingam, N., \& Schmidt, H. G. (2011). Characteristics of problems for problem-based learning: The students' perspective. Interdisciplinary Journal of Problem-Based Learning, 5(1), 6-33.

Susiani, Tri Saptuti, Salimi, Moh, and Hidayah , Ratna. (2018). Research Based Learning (RBL): How to Improve Critical Thinking Skills. EDP Sciences. SHS Web of Conferences 42, 00042

TIMSS \& PIRL. 2016. Trends International Mathematics and Science Study. Tersedia di https://timssandpirls.bc.edu/

Ulger, Kani. (2018). The Effect of Problem-Based Learning on the Creative Thinking and Critical Thinking Disposition of Students in Visual Arts Education. The Interdisciplinary Journal of Problem-based Learning. Volume 12, Issue 1. Page 3-6. 